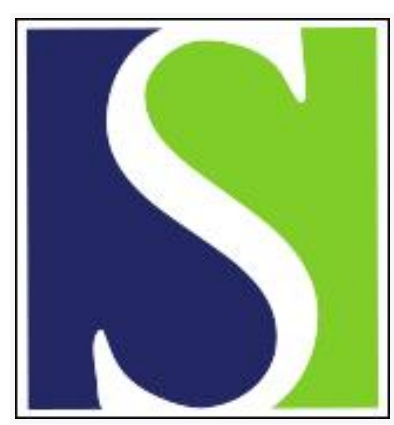

Scand J Work Environ Health 1994;20(2):132-138

https://doi.org/10.5271/sjweh.1420

Issue date: 01 Apr 1994

Exposure to power-frequency electromagnetic fields in Denmark.

by Skotte JH

Affiliation: National Institute of Occupational Health, Denmark.

This article in PubMed: www.ncbi.nlm.nih.gov/pubmed/8079135

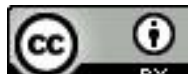




\title{
Exposure to power-frequency electromagnetic fields in Denmark
}

\author{
by Jørgen $\mathrm{H}$ Skotte, MSc(Eng) ${ }^{1}$
}

SKOTTE JH. Exposure to power-frequency electromagnetic fields in Denmark. Scand $J$ Work Environ Health 1994;20:132-8.

\begin{abstract}
OвJEctrves - The purpose of the study was to assess exposure to power-frequency electromagnetic fields in various groups with normal or high exposure in occupational and residential environments. Methods - Exposure to power-frequency $(50 \mathrm{~Hz})$ electric and magnetic fields was measured for $30 \mathrm{l}$ volunteers (396 measurements) in periods of $24 \mathrm{~h}$ in both occupational and residential environments. The study included electrical utility workers (generation, transmission, distribution, substation), office and industrial workers, and people living near high-power transmission lines. Electric and magnetic fields were measured with personal dosemeters, and the mean values were calculated for work and nonwork periods.

Results - The work-period magnetic field exposure, as the geometric mean of the distribution of the work-period means, for a group of selected industrial workers with high exposure was 6 [geometric standard deviation (GSD) 4.6] $\mu \mathrm{T}$. The exposure level was 0.10 (GSD 2.4) $\mu$ 'T for "normal" industrial workers and 0.09 (GSD 1.8) $\mu \mathrm{T}$ for office workers. For electrical utility workers the corresponding values were 0.72 (GSD 2.5) $\mu \mathrm{T}$ for substation workers, 0.52 (GSD 4.2) $\mu \mathrm{T}$ for generation workers, 0.36 (GSD 3.5) $\mu \mathrm{T}$ for transmission workers, and 0.15 (GSD 2.9) $\mu \mathrm{T}$ for distribution workers. The magnetic field exposure in normal residences was 0.04 (GSD 2.1) $\mu \mathrm{T}$, and in residences near high-power lines it was 0.29 (GSD 2.8) $\mu \mathrm{T}$. Corresponding results on exposure to electric fields are given in the study.

Conclusions - All of the measurements of exposure to electric and magnetic fields were below the values normally used as guidelines.
\end{abstract}

KEY TERMS - electric fields, high-power lines, magnetic fields, measurements, occupational, power frequency fields, residential.

Until recently, the assessment of exposure to extremely low-frequency or power-frequency electromagnetic fields has primarily been based on spot or point-in-time measurement with direct-reading handheld instrumentation. In the last few years dosemeters for the continuous recording of personal exposure have become commercially available and have made it possible to measure and describe long-term exposure $(1,2)$.

The purpose of this study was to assess exposure to power-frequency electromagnetic fields in both occupational and residential environments through a measurement program with personal dosemeters. An attempt was made to measure and compare the exposure of people in jobs with "high" and "normal" power-frequency fields and the exposure of people living in normal residences and those living in residences near high-power lines.

1 National Institute of Occupational Health, Denmark

Reprint requests to: J. Skotte, Arbejdsmiljøinstituttet, Lers $\emptyset$ Parkallé 105, DK-2100, Copenhagen, Denmark.

\section{Subjects and methods}

\section{Subjects}

The study included electric utility workers, people living near high-power lines, office workers, industrial workers, and others, for a total of 301 subjects and 396 measurements (table 1). There were 47 subjects with three measurements and one subject with two measurements. The multiple measurements, which were made for information on variations between work periods, were taken with a time interval of more than one week.

All of the subjects were volunteers and almost everyone asked was willing to participate.

Electric utilities. Workers were selected from the following five primary work environments: generation facilities, transmission lines (voltage above or equal to $50 \mathrm{kV}$ ), distribution lines (voltage less than $50 \mathrm{kV}$ ), substations, and other electrically and nonelectrically related jobs. For information on the number of workers engaged in these types of work environments a questionnaire was sent to all Danish utility companies. Workers from six of the companies were then selected to participate in the study. The subjects were not chosen according to a formal random scheme but were, instead, selected in col- 
laboration with the utilities to cover a broad range of different job types and tasks. The following types of jobs were represented: electricians, linesmen, facility operators, boilermen, smiths, engineers, mechanics, laborers, gardeners, surveyors, and others. The number of subjects in the study accounted for $2.5 \%$ of the workers in the five types of work environments in Danish utilities.

Residences near power lines. Seven different types of high-power line sections with voltages of $50 / 60$, $132 / 150$, and $400 \mathrm{kV}$ and two $132 \mathrm{kV}$ cables were selected. There were different combinations of single and double lines and closely spaced parallel lines with different voltages. The residences were randomly selected within $100 \mathrm{~m}$ from $400 \mathrm{kV}$ lines, $50 \mathrm{~m}$ from $132 / 150 \mathrm{kV}$ lines, and $25 \mathrm{~m}$ from $50 / 60 \mathrm{kV}$ lines, and $5 \mathrm{~m}$ from $132 \mathrm{kV}$ cables. A few examples (five) from residences nearby substation facilities were added to this group. Two of them were $60 \mathrm{kV}$ outdoor substations selected by the utilities and the last three were $10-\mathrm{kV}$ indoor substations known by the investigators.

Offices. The group working in an office environment included clerks, secretaries, managers, technical personnel, and others (outside the utility companies). The subjects were selected from eight public and private workplaces in 14 different sections. The subjects were chosen from workplaces known to the investigators through colleagues.

Industry. Two groups of industrial workers were formed, one with high exposure and one with normal exposure. The first was a specially selected group with jobs expected to have high exposure. It was made up of welders in a shipyard, electric furnace workers and electricians in a steel mill plant, electric furnace workers in a chemical plant, electric railroad engineers, and a laboratory technician working with a spectrophotometer. The workplaces in this group were selected in collaboration with the Danish Working Environment Service. The normal exposure group comprised workers with exposure in an automobile repair shop, a plate shop, a machine shop, a laboratory, and a plant producing telecommunication equipment. This group of industrial workplaces was based on contacts established before the study for other reasons than power-frequency fields and was found convenient to include in the study to represent very common industrial activities.

\section{Instrumentation}

Eight personal dosemeters of the Positron type were used. The dosemeters measure $50-\mathrm{Hz}$ electric and magnetic fields and high-frequency $(5-20 \mathrm{MHz})$ electromagnetic fields. The dynamic range was
$0.01-200 \mu \mathrm{T}$ for the magnetic fields and 0.6 $10000 \mathrm{~V} \cdot \mathrm{m}^{-1}$ for the electric fields, and the values were classified into 16 logarithmic equally spaced bins (4-bit resolution). This type of dosemeter has a narrow band frequency response $(3 \mathrm{~dB}$ points at $42 \mathrm{~Hz}$ and $60 \mathrm{~Hz}$ ) and measures magnetic fields in three perpendicular directions.

One magnetic field meter of the type Combinova MFM10 was used. This handheld meter measures magnetic fields in three directions in the range of $0.01 \mu \mathrm{T}-10 \mathrm{mT}$. It is a broad-band instrument (5$1000 \mathrm{~Hz}$ ).

One dosemeter of the type Emdex II was used. It is a broad-band magnetic field dosemeter with a dynamic range of $0.01-300 \mu \mathrm{T}$ and a resolution of $0.1 \%$ (10 bits). With this dosemeter simultaneous measurements can be made in the broad-band range of $40-800 \mathrm{~Hz}$ with power-frequency harmonics and in the range of $40-100 \mathrm{~Hz}$ without power frequency harmonics.

Before the measurement program was started, the characteristics of the dosemeters were tested by checking calibration, linearity, frequency response, directivity, the timing and influence of temperature variations, and electromagnetic interference. The calibration check was made according to standard procedures (3), and it was carried out regularly (after every five measurements).

\section{Measurement procedures}

All measurements of exposure were carried out with the Positron dosemeters. The Combinova magnetic field meter was used for additional point-in-time measurements for industrial workers in cases in which high levels of magnetic fields capable of over-

Table 1. Number of subjects and measurements.

\begin{tabular}{|c|c|c|}
\hline Groups & $\begin{array}{l}\text { Subjects } \\
\text { (N) }\end{array}$ & $\begin{array}{l}\text { Measure- } \\
\text { ments } \\
(\mathrm{N})\end{array}$ \\
\hline \multicolumn{3}{|l|}{ Electric utility workers } \\
\hline $\begin{array}{l}\text { Generation facility } \\
\text { Transmission line } \\
\text { Distribution line } \\
\text { Substation } \\
\text { Other }\end{array}$ & $\begin{array}{l}46 \\
13 \\
33 \\
22 \\
15\end{array}$ & $\begin{array}{l}65 \\
17 \\
51 \\
46 \\
17\end{array}$ \\
\hline \multicolumn{3}{|c|}{$\begin{array}{l}\text { People living near electric } \\
\text { power facilities }\end{array}$} \\
\hline $\begin{array}{l}\text { Power line } \\
\text { Cable } \\
\text { Substation }\end{array}$ & $\begin{array}{r}38 \\
6 \\
5\end{array}$ & $\begin{array}{r}38 \\
6 \\
5\end{array}$ \\
\hline Office workers & 55 & 83 \\
\hline \multicolumn{3}{|l|}{ Industry } \\
\hline $\begin{array}{l}\text { High exposure } \\
\text { Normal exposure }\end{array}$ & $\begin{array}{l}24 \\
30\end{array}$ & $\begin{array}{l}24 \\
30\end{array}$ \\
\hline Other & 14 & 14 \\
\hline Total & $301^{a}$ & $396^{a}$ \\
\hline
\end{tabular}


loading the dosemeters were found. The Emdex II dosemeter was used in additional measurements to quantify the influence of power-frequency harmonics.

The study consisted in 24-h measurements with dosemeters sampling field strength every $5 \mathrm{~s}$. The dosemeter was normally worn in a leather case attached to a belt at the hip. In a few cases the dosemeter was worn in a trouser or shirt pocket. The display of the dosemeter was switched off during the measurement.

The subjects wore the dosemeter at work, at home, during travel, and so forth, and they recorded the times for these activities in a personal logbook. The subjects were instructed to put the dosemeter near their bed at night, but not close to an electric watch, a clockradio, or the like. Immediately after the measurement was finished, the data were transmitted to a portable computer, after which the recordings were shown and explained to the subject.

During the dosemeter measurement in residences near high-power lines the utility companies recorded the current load of the lines, and afterwards the distance from the right-of-way center to the nearest part of the residence was measured.

\section{Data analysis}

After the measurements the dosemeter data and the logbook record of the subjects were checked for any indications of violation of the measurement protocol. For this purpose the recordings of electric field strength were useful because normally the electric field shows considerable fluctuations if measured at the surface of the human body, owing to body movements and field perturbations. Contrarily, a stationary measurement away from the body will

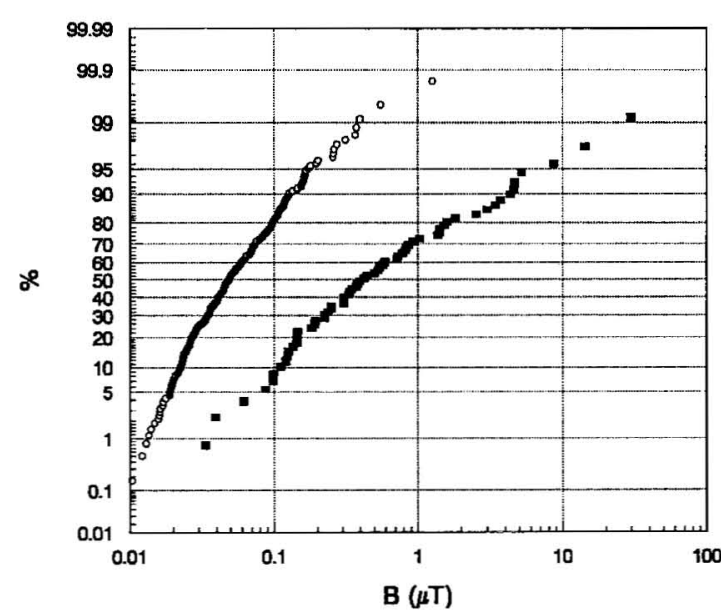

Figure 1. Log probability plot of magnetic field means. $\mathbf{\square}=$ work-period means for generation facility workers, $\mathrm{O}=$ all nonwork means for subjects with residences far from highpower lines. show long periods with constant electric field recordings. When such recordings were found, it was taken to suggest that the dosemeter had not been worn and these periods were excluded from further analysis.

According to the logbook the dosemeter measurements were divided into periods according to the following four types of activities: (i) work (ie, time at the workplace), (ii) periods neither at the workplace nor at home (commuting, shopping, visiting, and other nonwork, nonresidential activities), (iii) periods at home with the dosemeter worn (daytime), and (iv) periods at home without the dosemeter being worn (nighttime).

Normally a dosemeter measurement had more periods of the same type, especially types 1,2 , and 3 , depending on the starting time of the measurement. All periods with the same type of activity were combined, and the distribution of the measurement values in the 16 bins of the dosemeter was calculated for the four types of activities. In this way every dosemeter measurement containing a large number of single values was reduced to data on four distributions corresponding to the four types of activities for the subject. From these distributions on personal exposure, several statistical parameters could be calculated, but in this study it was decided to use the arithmetic mean as the parameter describing the exposure of the subjects.

All multiple measurements made for some of the subjects were included in the analysis in the same way as the single measurement for the rest of the subjects.

\section{Results}

The total approved time of measurement was 8894 $\mathrm{h}$, an average of $22.5 \mathrm{~h}$ per dosemeter measurement.

\section{Magnetic field}

Figure 1 shows the work-period magnetic field means for the generator facility workers and the nonwork magnetic field means for all of the subjects with residences distant to high-power lines. The distributions of the means were highly skewed. Therefore the exposure of the groups has been characterized in tables $2-4$ with the following statistical parameters: maximum; minimum; 5th, 25th, 50th, 75th and 95th percentiles; mean; standard deviation; geometric mean; and geometric standard deviation. The distributions of the work-period means are given in table 2 for the main groups and in table 3 for the subgroups of utility workers. The corresponding means for the nonwork periods are given in table 4 . On the basis of the data in tables $2-4$, figure 2 compares the distributions of the work-period means for the groups and also shows the aggregated distribution of the means for the nonwork periods for the subjects living far from power lines. 
Table 2. Distribution of the work-period magnetic field means $(\mu T)$. $(N=$ number of measurements, Min $=$ minimum, Max = maximum, SD = standard deviation, $\mathrm{GM}=$ geometric mean, GSD = geometric standard deviation)

\begin{tabular}{|c|c|c|c|c|c|c|c|c|c|c|c|c|c|}
\hline \multirow{2}{*}{ Statistic } & & \multirow{2}{*}{$N$} & \multirow{2}{*}{ Min } & \multicolumn{5}{|c|}{ Percentile } & \multirow{2}{*}{ Max } & \multirow{2}{*}{ Mean } & \multirow{2}{*}{$\mathrm{SD}$} & \multirow{2}{*}{$\mathrm{GM}$} & \multirow{2}{*}{ GSD } \\
\hline & & & & 5 th & 25 th & 50 th & 75 th & 95th & & & & & \\
\hline \multicolumn{2}{|l|}{ Utility } & 195 & 0.02 & 0.04 & 0.14 & 0.36 & 0.93 & 3.50 & 29.71 & 0.97 & 2.54 & 0.37 & 2.68 \\
\hline \multicolumn{2}{|c|}{ Residence near power line } & $24^{a}$ & 0.01 & 0.01 & 0.03 & 0.07 & 0.15 & 0.49 & 0.49 & 0.10 & 0.11 & 0.07 & 2.76 \\
\hline \multicolumn{2}{|l|}{ Office } & 83 & 0.02 & 0.03 & 0.07 & 0.10 & 0.14 & 0.20 & 0.25 & 0.10 & 0.05 & 0.09 & 1.80 \\
\hline \multicolumn{14}{|l|}{ Industry } \\
\hline \multicolumn{2}{|c|}{$\begin{array}{l}\text { High exposure } \\
\text { Normal exposure }\end{array}$} & $\begin{array}{l}24^{b} \\
30\end{array}$ & $\begin{array}{l}0.41 \\
0.01\end{array}$ & $\begin{array}{l}0.41 \\
0.02\end{array}$ & $\begin{array}{l}1.90 \\
0.08\end{array}$ & $\begin{array}{l}6.00 \\
0.12\end{array}$ & $\begin{array}{l}20 \\
0.20\end{array}$ & $\begin{array}{l}70 \\
0.35\end{array}$ & $\begin{array}{l}70 \\
0.40\end{array}$ & $\begin{array}{r}15.34 \\
0.14\end{array}$ & $\begin{array}{r}20.29 \\
0.10\end{array}$ & $\begin{array}{l}6.00 \\
0.10\end{array}$ & $\begin{array}{l}4.58 \\
2.38\end{array}$ \\
\hline \multicolumn{14}{|c|}{$\begin{array}{l}\text { a Twenty-five individuals were unemployed or were omitted because of their workhours were less than } 4 \mathrm{~h} \text { the day of the mea- } \\
\text { surement. } \\
\text { bight dosemeter measurements were corrected for dosemeter overrange values on the basis of measurements with the Com- } \\
\text { binova magnetic field meter. }\end{array}$} \\
\hline \multicolumn{14}{|c|}{$\begin{array}{l}\text { Table 3. Distribution of the work-period magnetic field means }(\mu T) \text { for the subgroups of utility workers. ( } N=\text { number of mea } \\
\text { surements, } \mathrm{Min}=\text { minimum, Max }=\text { maximum, } \mathrm{SD}=\text { standard deviation, } \mathrm{GM}=\text { geometric mean, GSD }=\mathrm{geometric} \text { standaro } \\
\text { deviation) }\end{array}$} \\
\hline \multirow{2}{*}{ Statistic } & \multirow{2}{*}{$\mathrm{N}$} & \multirow{2}{*}{ Min } & \multicolumn{5}{|c|}{ Percentile } & \multirow{2}{*}{\multicolumn{2}{|c|}{ Max }} & \multirow{2}{*}{ Mean } & \multirow{2}{*}{$\mathrm{SD}$} & \multirow{2}{*}{ GM } & \multirow{2}{*}{ GSD } \\
\hline & & & 5 th & 25 th & 50 th & 75th & 95th & & & & & & \\
\hline Utility & 64 & 0.03 & 0.07 & 0.18 & 0.41 & 1.41 & 8.00 & 29 & & 1.72 & 4.23 & 0.52 & 4.18 \\
\hline Transmission & 17 & 0.04 & 0.04 & 0.12 & 0.56 & 1.60 & 1.73 & & & 0.67 & 0.66 & 0.36 & 3.49 \\
\hline Distribution & 51 & 0.02 & 0.03 & 0.09 & 0.14 & 0.27 & 1.50 & & & 0.29 & 0.47 & 0.15 & 2.92 \\
\hline Substation & 46 & 0.08 & 0.11 & 0.39 & 0.89 & 1.36 & 2.50 & & & 1.02 & 0.94 & 0.72 & 2.46 \\
\hline Other & 17 & 0.03 & 0.03 & 0.12 & 0.36 & 0.50 & 1.03 & & & 0.38 & 0.28 & 0.27 & 2.58 \\
\hline
\end{tabular}

Table 4. Distribution of the magnetic field means $(\mu \mathrm{T})$ for all nonwork periods, at home (daytime and nighttime) and not at home. ( $N=$ number of measurements, Min = minimum, Max = maximum, $S D=$ standard deviation, $\mathrm{GM}=\mathrm{geometric}$ mean, $\mathrm{GSD}=\mathrm{geo}$ metric standard deviation)

\begin{tabular}{|c|c|c|c|c|c|c|c|c|c|c|c|c|}
\hline \multirow{2}{*}{ Statistic } & \multirow{2}{*}{$\mathbf{N}$} & \multirow{2}{*}{ Min } & \multicolumn{5}{|c|}{ Percentile } & \multirow{2}{*}{$\operatorname{Max}$} & \multirow{2}{*}{ Mean } & \multirow{2}{*}{ SD } & \multirow{2}{*}{ GM } & \multirow{2}{*}{ GSD } \\
\hline & & & 5 th & 25 th & 50 th & 75 th & 95th & & & & & \\
\hline Utility & 161 & 0.01 & 0.02 & 0.03 & 0.04 & 0.08 & 0.18 & 0.74 & 0.07 & 0.09 & 0.05 & 2.15 \\
\hline Residence near power line & 49 & 0.03 & 0.05 & 0.12 & 0.24 & 0.68 & 1.54 & 2.20 & 0.44 & 0.48 & 0.27 & 2.80 \\
\hline Office & 79 & 0.01 & 0.02 & 0.03 & 0.05 & 0.09 & 0.18 & 0.31 & 0.07 & 0.05 & 0.05 & 1.93 \\
\hline \multicolumn{13}{|l|}{ Industry } \\
\hline $\begin{array}{l}\text { High exposure } \\
\text { Normal exposure }\end{array}$ & $\begin{array}{l}19 \\
29\end{array}$ & $\begin{array}{l}0.01 \\
0.01\end{array}$ & $\begin{array}{l}0.01 \\
0.01\end{array}$ & $\begin{array}{l}0.04 \\
0.03\end{array}$ & $\begin{array}{l}0.06 \\
0.06\end{array}$ & $\begin{array}{l}0.10 \\
0.12\end{array}$ & $\begin{array}{l}0.40 \\
0.80\end{array}$ & $\begin{array}{l}0.40 \\
1.27\end{array}$ & $\begin{array}{l}0.09 \\
0.12\end{array}$ & $\begin{array}{l}0.11 \\
0.23\end{array}$ & $\begin{array}{l}0.06 \\
0.06\end{array}$ & $\begin{array}{l}2.40 \\
2.55\end{array}$ \\
\hline All no-line residences & 298 & 0.01 & 0.02 & 0.03 & 0.05 & 0.08 & 0.17 & 1.27 & 0.07 & 0.09 & 0.05 & 2.08 \\
\hline
\end{tabular}

a One person belonging to the utility group, who happened to liver near a high-power line, is not included in the analysis.

The exposure of the group with residence near high-power lines and that of the group with residences far from high-power lines is compared in figure 3 . The distance of the near-line residences to the nearest high-power line varied between 0 and $68 \mathrm{~m}$ with a mean of $23 \mathrm{~m}$. The average current load during the exposure measurements was $60-610 \mathrm{~A}$ with a mean of $290 \mathrm{~A}$.

Figure 4 shows an example of accumulated magnetic field exposure (microteslas times hours) for 24 $\mathrm{h}$ for the work and nonwork periods. The figure is based on the work and nonwork geometric means of the groups in tables $2-4$ ( $8 \mathrm{~h}$ of work and $16 \mathrm{~h}$ of nonwork).
In 26 of the 396 dosemeter measurements there were short periods of magnetic fields greater than $200 \mu \mathrm{T}$ (ie, above the dynamic range of the dosemeter). These peaks occurred especially in the industrial group with high exposure (14 measurements). Where possible, additional measurements of the true peak level (and duration) were made with the Combinova field meter, and the magnetic field means were corrected accordingly. Peak levels at $1-2 \mathrm{mT}$ were found for the electric furnace workers.

Fifteen measurements in periods of 4 to $24 \mathrm{~h}$ were made with the Emdex II meter. The mean magnetic field showed, on the average, a $12 \%$ higher (maximum $25 \%$ ) value when the harmonics to the power 


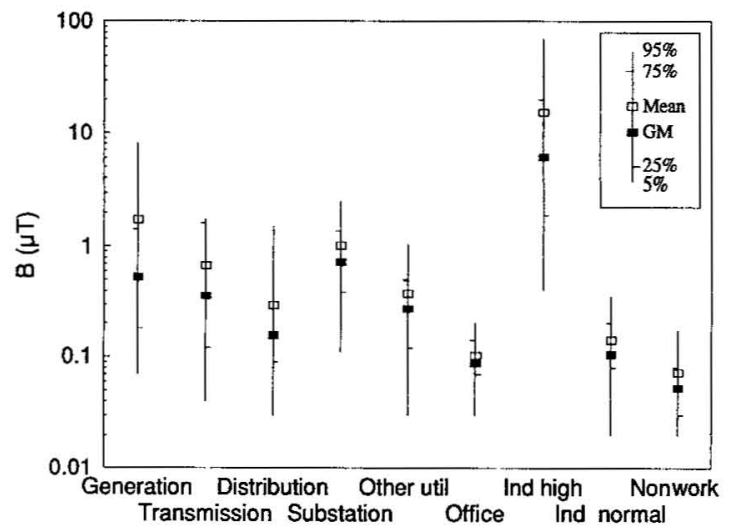

Figure 2. Distribution of work-period means for magnetic fields for five subgroups of utility workers, the office workers, and the two groups of industrial workers and the distribution of the nonwork means for all of the groups (all measurements for subjects with residences far from power lines). ( $G M=$ geometric mean, ind = industrial, util = utilities)

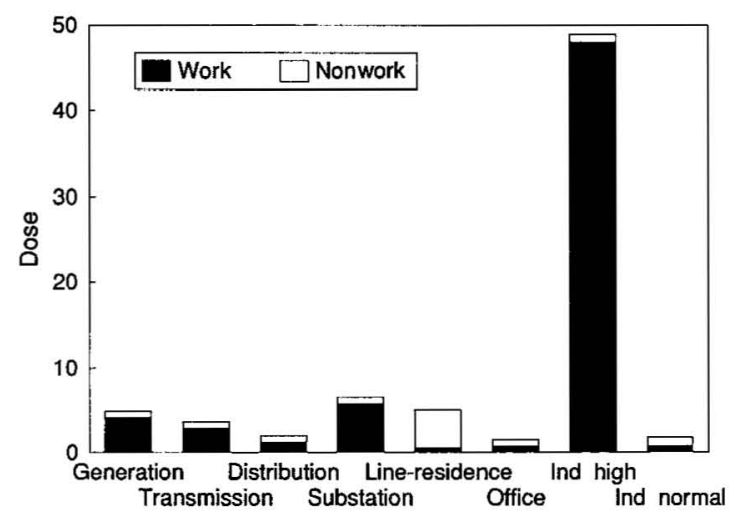

Figure 4. Magnetic field "dose" in microteslas times hours for a $24-h$ period. (ind = industrial)

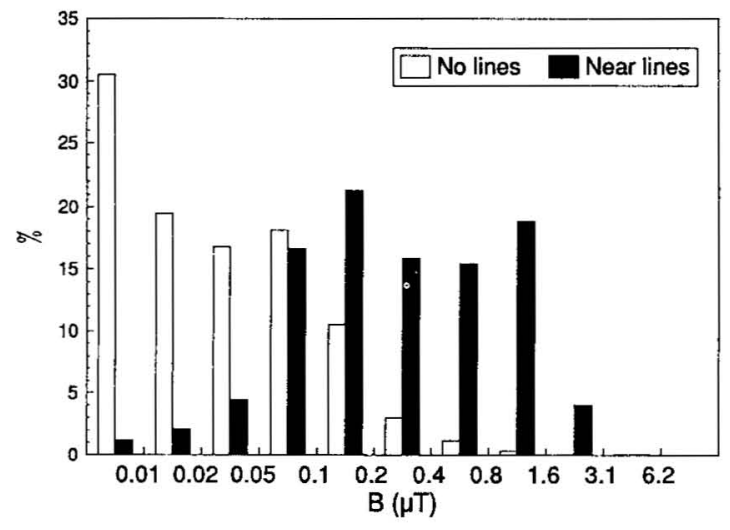

Figure 3. Distribution of magnetic field means in residences near power lines compared with those in all other residences far from power lines. The exposure means were calculated for all the time at home (both daytime and nighttime). Measurements with a total time at home of $<7 \mathrm{~h}$ were excluded. (no-line residences: $N=296$, geometric mean $=$ $0.040 \mu \mathrm{T}$, mean $=0.062 \mu \mathrm{T}$; near-line residences: $N=50$, geometric mean $=0.29 \mu \mathrm{T}$, mean $=0.49 \mu \mathrm{T}$, maximum $=$ $2.24 \mu \mathrm{T})$

frequency were included than without the harmonics included in the calculation of the mean.

\section{Electric field}

Data on electric fields measured at the same time as the magnetic fields are given in tables 5 and 6 . The distributions of the electric work-period means for the main groups and the residential means are given in table 5 , and the distributions of the electric field work-period means for the subgroups of utility workers are presented in table 6 . Figure 5 compares the distributions of the work-period means for the groups and also shows the aggregated distribution of the means for the nonwork periods for subjects living far from power lines. The nighttime without the dosemeter was excluded in the calculation of the means.

Table 5. Distribution of the electric field means $\left(\mathrm{V} \cdot \mathrm{m}^{-1}\right)$. The nighttime periods were excluded before the calculation of the electric mean values for nonwork and at home periods. $(\mathrm{N}=$ number of measurements, Min $=$ minimum, Max $=$ maximum, $\mathrm{SD}=$ standard deviation, $\mathrm{GM}=$ geometric mean, $\mathrm{GSD}=$ geometric standard deviation)

\begin{tabular}{|c|c|c|c|c|c|c|c|c|c|c|c|c|}
\hline \multirow{2}{*}{ Statistic } & \multirow{2}{*}{$N$} & \multirow{2}{*}{ Min } & \multicolumn{5}{|c|}{ Percentile } & \multirow{2}{*}{ Max } & \multirow{2}{*}{ Mean } & \multirow{2}{*}{ SD } & \multirow{2}{*}{ GM } & \multirow{2}{*}{ GSD } \\
\hline & & & 5 th & 25 th & 50 th & 75 th & 95 th & & & & & \\
\hline \multicolumn{13}{|l|}{ Work period } \\
\hline $\begin{array}{l}\text { Utility } \\
\text { Office }\end{array}$ & $\begin{array}{c}195 \\
83\end{array}$ & $\begin{array}{l}1.4 \\
2.1\end{array}$ & $\begin{array}{l}3.0 \\
5.0\end{array}$ & $\begin{array}{l}5.4 \\
9.1\end{array}$ & $\begin{array}{l}11.3 \\
12.0\end{array}$ & $\begin{array}{l}22.1 \\
19.1\end{array}$ & $\begin{array}{r}250.0 \\
39.5\end{array}$ & $\begin{array}{r}1482.3 \\
56.7\end{array}$ & $\begin{array}{l}46.1 \\
15.6\end{array}$ & $\begin{array}{r}134.5 \\
10.3\end{array}$ & $\begin{array}{l}14.0 \\
13.0\end{array}$ & $\begin{array}{l}3.6 \\
1.8\end{array}$ \\
\hline \multicolumn{13}{|l|}{ Industry } \\
\hline $\begin{array}{l}\text { High exposure } \\
\text { Normal exposure }\end{array}$ & $\begin{array}{l}24 \\
30\end{array}$ & $\begin{array}{l}1.8 \\
3.8\end{array}$ & $\begin{array}{l}2.0 \\
4.4\end{array}$ & $\begin{array}{l}7.9 \\
9.3\end{array}$ & $\begin{array}{l}12.0 \\
13.0\end{array}$ & $\begin{array}{l}18.9 \\
18.5\end{array}$ & $\begin{array}{l}40.0 \\
50.0\end{array}$ & $\begin{array}{l}41.2 \\
61.2\end{array}$ & $\begin{array}{l}15.1 \\
16.0\end{array}$ & $\begin{array}{l}10.3 \\
11.5\end{array}$ & $\begin{array}{l}12.0 \\
13.4\end{array}$ & $\begin{array}{l}2.1 \\
1.8\end{array}$ \\
\hline \multicolumn{13}{|l|}{ Nonwork } \\
\hline $\begin{array}{l}\text { Residence not near } \\
\text { power line }\end{array}$ & 295 & 2.1 & 5.8 & 12.7 & 15.7 & 22.4 & 43.5 & 76.6 & 18.8 & 12.5 & 15.7 & 1.8 \\
\hline \multicolumn{13}{|l|}{ At home } \\
\hline $\begin{array}{l}\text { Residence not near } \\
\text { power line } \\
\text { Residence near }\end{array}$ & 267 & 1.1 & 5.7 & 12.2 & 17.5 & 25.0 & 47.0 & 91.0 & 21.0 & 14.7 & 17.1 & 1.9 \\
\hline power line & 49 & 7.3 & 8.6 & 14.3 & 21.9 & 31.0 & 91.0 & 117.3 & 29.2 & 24.1 & 23.0 & 1.9 \\
\hline
\end{tabular}


Table 6. Distribution of the work-period electric field means $\left(\mathrm{V} \cdot \mathrm{m}^{-1}\right)$ for the subgroups of utility workers. $(\mathrm{N}=$ number of mea. surements, Min = minimum, Max=maximum, $\mathrm{SD}=$ standard deviation, $\mathrm{GM}=$ geometric mean, $\mathrm{GSD}=$ geometric standard deviation)

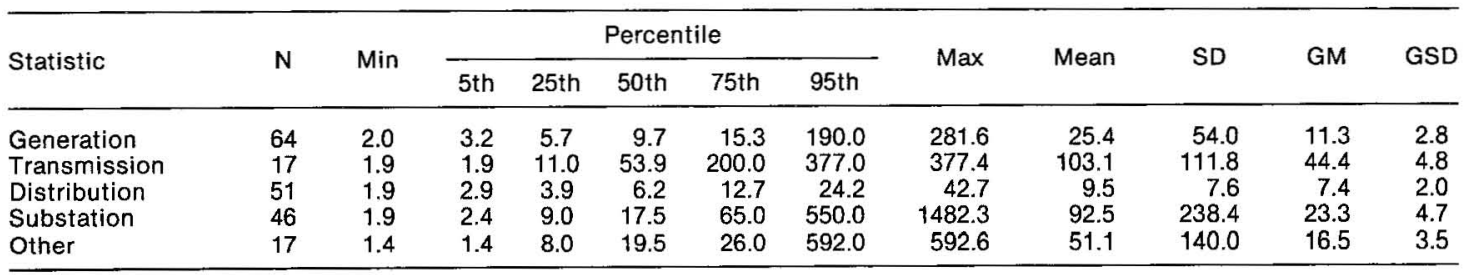

Only six dosemeter measurements, of which four were for linemen, showed short periods with readings greater than $10 \mathrm{kV} \cdot \mathrm{m}^{-1}$ (ie, above the dynamic range of the dosemeter).

\section{Discussion}

\section{Magnetic field}

Large variations in the work period means for the magnetic fields were evident in the utility and highexposure industrial groups, while comparably smaller variations were found for the other groups. The smallest variations were found for the office workers.

The exposure of workers in offices and the normal-exposure industrial groups was similar and very much lower than in the high-exposure industrial group. In the electric utilities the subgroups with the highest work-period exposure were the substation workers and the generator facility workers, and the group with the lowest was the distribution workers. The large variations in exposure among the transmission line workers and the generator facility workers were related to variations in tasks, which sometimes involved work close to live power systems or work on grounded systems distant to live power systems.

There were no differences in the nonwork exposure of the groups for all of the subjects with residences far from power lines. There was a slight tendency towards lower nighttime exposure than daytime exposure. During commuting by car, train, and the like, the exposure was the same in all of the groups.

In a comparison of the exposure in residences near power lines versus exposure in those far from power lines (figure 3), it was found that individuals with a mean exposure of $0.1 \mu \mathrm{T}$ appeared in both groups, but the geometric mean for the near-line group was seven times higher than the geometric mean for the residences far from power lines. Average exposure above $0.2 \mu \mathrm{T}$, which was typical for near-line residences, was infrequent in residences far from power lines. Exposure below $0.05 \mu \mathrm{T}$, which was typical for residences far from power lines, was infrequent in residences near power lines.

The 24-h "magnetic field dose" plot in figure 4 shows that the average "dose" for the generator facility, transmission line, and substation workers was

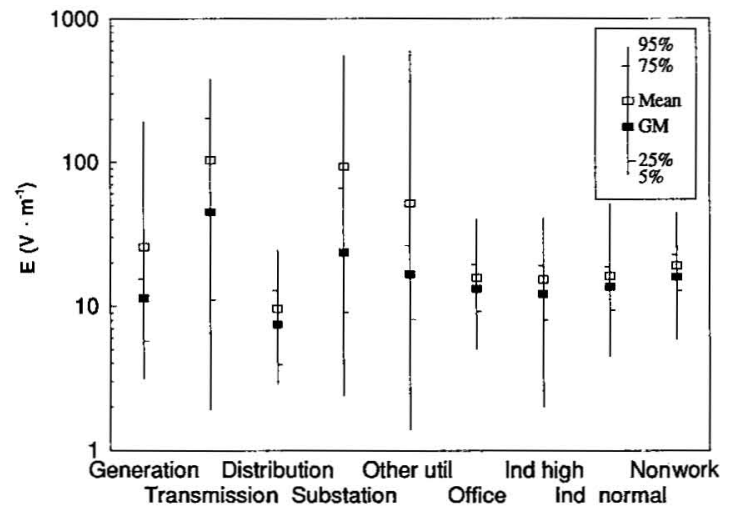

Figure 5. Distribution of work-period means for electric fields for five subgroups of utility workers, the office workers, and the two groups of industrial workers and the distribution of nonwork means for all of the groups. (All of the measurements are for subjects with residences far from power lines.) ( $\mathrm{GM}=$ geometric mean, ind = industrial, util = utilities $)$

roughly the same as for people living in residences near power lines (approximately $5 \mu \mathrm{T}$. hours), but the relationship was reversed between work and nonwork exposure. The average "dose" in the high-exposure industrial group was roughly 35 times higher than the average "dose" of the office and normalexposure industrial groups.

Figure 6 compares the results of this study with the results of the American Emdex project (2) and shows that the exposure of the generator facility and substation workers was nearly the same but that the exposure of the transmission and distribution workers in this study was half the exposure found in the Emdex project. This difference might have been caused by differences in the transmission and distribution systems or by differences in work conditions. The exposure in Danish residences is about half the exposure in American residences. A part of this difference might have been caused by harmonics to the power frequency, because the dosemeter used in this study was a narrow-band type $(42-60 \mathrm{~Hz})$ and the dosemeter in the American study was a broad-band type (Emdex I, 35-300 Hz). The measurements made in this study with the Emdex II instruments showed average differences of $12 \%$ between measurements with versus without harmonics; therefore the main cause of the differences in magnetic field 


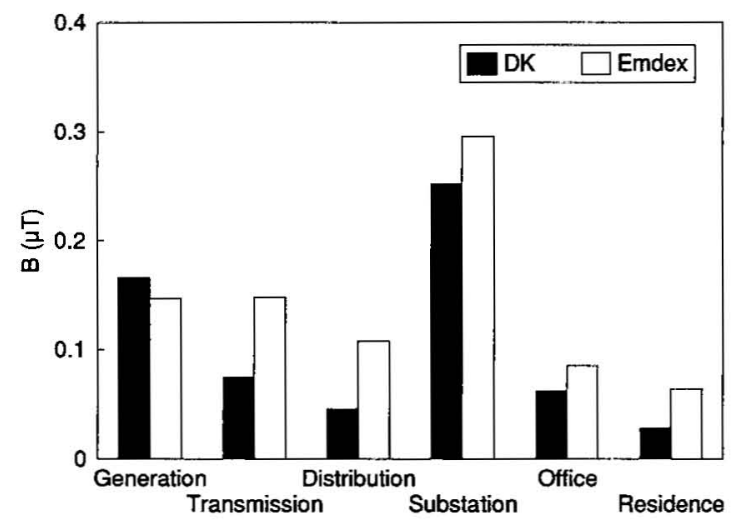

Figure 6. Comparison of results on magnetic field exposure in this study using Positron dosemeters (DK) and the American Emdex project using broad-band width dosemeters (Emdex) using data on the geometric mean for instantaneous measurement values. The data on the utility groups and the office group are valid for the work periods, and the residential data are the corresponding aggregated measurements for these groups.

exposure in Danish and American residences was probably due to differences in wiring and the current load of the power distribution systems.

The analyses in tables $2-4$ were repeated with the exclusion of the second and third measurements made for 47 subjects with multiple measurements (mainly in the generation, distribution, substation, office and residence groups) (table 1). In all of the groups except the generation group, this procedure resulted in insignificant changes. In the generation group the geometric mean of the work-period means changed from 0.52 to $0.36 \mu \mathrm{T}$ when the multiple measurements were excluded. This change indicates that the multiple measurements in this group were somewhat biased by high exposure. Generally it should be noted that the subjects in the study were selected from volunteers and some of the groups were small; therefore bias cannot be ruled out. Especially the two industrial groups should only be considered as preliminary examples of industrial exposure.

\section{Electric fields}

Measurements of electric fields with personal dosemeters involve large uncertainties because the body, the posture, the position of the dosemeter, and the like can substantially influence the electric field (2, 4). For this reason the results should be interpreted with great caution, especially if compared with those of other studies.

The influence of the body, dosemeter position, and the like is normally described by the enhancement factor, which is defined as the ratio of field measured by the dosemeter on the body and the unperturbed electric field. Laboratory experiments (5) have shown that 1.0 would be a reasonable average enhancement factor for a dosemeter worn attached to a belt at the hip.
As expected, the work-period exposure was generally the highest for the transmission line workers, but there were large variations in this group and in the substation group. The variations were related to different tasks involving work on live or grounded systems. Typical work-period exposure for the office and industrial workers and average residential exposure was $10-20 \mathrm{~V} \cdot \mathrm{m}^{-1}$. There was no significant difference in the mean electric field exposure between residences near power lines and those far from power lines.

\section{Compliance with standards}

All of the results of the measurements of exposure to electric and magnetic fields in this study were clearly below normally used guidelines on limits of exposure to power-frequency fields. The IRPA/ INIRC (International Non-ionizing Radiation Committee of the International Radiation Protection Association) guidelines (6) recommend that continuous occupational exposure during the workday should be limited to $10 \mathrm{kV} \cdot \mathrm{m}^{-1}$ for electric fields and $500 \mu \mathrm{T}$ for magnetic fields. The highest mean exposure for work-period electric fields was approximately $1.5 \mathrm{kV} \cdot \mathrm{m}^{-1}$ for a substation worker, and the highest work-period mean exposure for magnetic fields was approximately $70 \mu \mathrm{T}$ for a welder and a electric furnace worker.

\section{Acknowledgments}

The study was financially supported by the Association of Danish Electric Utilities.

\section{References}

1. Deadman JE, Camus M, Armstrong BG, Héroux D, Cyr $\mathrm{M}$, Plante $\mathrm{M}$, et al. Occupational and residential $60-\mathrm{Hz}$ electromagnetic fields and high-frequency electric transients: exposure assessment using a new dosimeter. Am Ind Assoc J 1988:49(8);409-19.

2. Bracken DT. The Emdex project. Palo Alto, CA: Electric Power Research Institute, 1990. (Interim report EPRI EN-7048.)

3. Institute of Electrical and Electronics Engineers (IEEE). Standard procedures for measurements of power frequency electric and magnetic fields from AC power lines, New York, NY: IEEE, 1987. (ANSI/IEEE Std 644-1987.)

4. Chartier VL, Bracken DT, Capon AS. BPA study of occupational exposure to $60-\mathrm{Hz}$ electric fields. IEEE Trans Power Appar Syst 1985:104;733 - 44.

5. Skotte J. Eksponering for elektromagnetiske $50 \mathrm{~Hz}$ felter [Exposure to power frequency electromagnetic fields]. Copenhagen: National Institute of Occupational Health, 1993. (AMI report; no 40.)

6. International Non-ionizing Radiation Committee of the International Radiation Protection Association (IRPA/ INIRC). Interim guidelines on limits of exposure to 50/ $60 \mathrm{~Hz}$ electric and magnetic fields. Health Phys 1990: $58(1) ; 113-22$.

Received for publication: 25 February 1993 